\title{
Enactments in Interaction Design: How Designers Make Sketches Behave
}

\author{
by Mattias Arvola, Linköpings Universitet, Linköping, Sweden \\ and Henrik Artman, The Royal Institute of Technology (KTH), Computer Sience and Communication, \\ Stockholm, Sweden
}

\begin{abstract}
How do designers of interactive media work on the dynamic aspects of their designs? Previous research has emphasized the role of gestures to express what users and computers do. This paper contributes with a detailed analysis of interaction designers' enactments in terms of what they express using a model of interaction design based on five domains: design concept, functions and content, structure, interaction, and presentation. Two enactive means of expression are identified: interaction walkthrough and improvised role play. Gestures drive the interaction walkthrough and scenarios created on the spot drive the improvised role play. In terms of the suggested model of interaction design, interaction walkthroughs start out in the domain of interaction, and improvised role play starts out in the domain of design concept. From these domains the designer can then see consequences for the other domains of interaction design. The five domains of interaction design can be used as an analytical tool for thoughtful reflection, and interaction walkthroughs and improvised role play can be articulated as conscious means of expression.
\end{abstract}

Keywords: Design representations, gestures, interaction design, means of expression, models, performance, sketching

\section{INTRODUCTION}

The object for design in interaction design is dynamic and experiential: ways of interacting and using a system (Arvola, 2005, 2006). Designers who work in the area of interaction design need to represent ways for people to interact, they need to represent usage, and they need to represent user experiences. Sketching in interaction design accordingly differs from sketching in other domains due to the explicit focus on expressing kinaesthetic experience, interactivity, temporal aspects, tangibility, immersion, sound, and haptics (Svanæs, 2000; Fällman, 2003). Sketching in interaction design needs to be both static and temporal (Löwgren, 2004). The overarching problem that this paper addresses is how interaction designers express the dynamics of interaction: from user interface elements to the design concept and the business relations that surround it. A short and less analytical version of this paper was presented at the workshop Design and semantics of form and movement DeSForM 2006 (Arvola \& Artman, 2006).

We shall present an analysis of how collaborating designers portray interaction by taking on the role of another person or a system component. The designers in our study create a composition in combinations of motivation, actions, linguistic expressions, argumentation, and graphical representations.

In the following background we shall cover the role of models and sketches in design, how interaction designers typically sketch interaction flows, and some research on both planned and situated enactments to express interaction. Finally, we present a model of interaction design, describing different levels of detail of the design object, which we shall use to analyse what collaborating interaction designers express in their situated enactments of interaction.

\section{The role of model-making in design}

Designers always use sketches and models. When designers perform acts on their models we say that they act in the action context; that is, here and now in the workplace activity (Tang, 1989; Artman et al., 2005). The models, however, are also representations of what will happen in the target context, in the virtual world of hypothetical user activity where a future design solution will be used (Schön, 1983; Tuikka, 2002).

Models are also used to communicate ideas and understand the design situation (Nelson \& Stolterman, 2003; Sundholm et al., 2004; Lantz et al., 2005). The understanding emerges in quick loops of making exploratory design moves in the model, seeing the effects, and assessing the holistic consequences (Arvola, 2005). Models and representations also satisfy the need to propose, discuss, and evaluate design collaboratively.

Sketching is a particularly quick way to create and assess design alternatives. As the designer sketches, the representation of a design idea creates further ideas, and helps designers to reframe their design problem. In fact, the sketch can precede the thought and hence drive the cognitive process (Schö n, 1987; Fleming, 1998). Designers reflect on their sketches in both acts of "seeing as" and acts of "seeing that" (Goldschmidt, 1991). Seeingas stimulates new ideas, while seeing-that prompts assessment of consequences.

Designers tend to talk and draw simultaneously, a phenomenon called spatial-action language (Schö $n$, 1987). The sketch as such can be seen as a material anchor (Hutchins, 2005) for complex design concepts and their implications: it holds the design in place and makes it stable enough to reason about. 


\section{Sketching interaction flows}

In interaction design, computer prototypes are usually built to represent and communicate the dynamics of a working interactive system. Before such prototypes can be built, however, the dynamics must be represented in other ways and state transition charts are one such way.

As seen in studies performed by Newman \& Landay (2000) and by Lantz et al. (2005) designers often use storyboards as well as navigation structures (site maps) to describe the flows of users' interactions.

Site maps are one type of state-transition chart. They describe the states that are possible for a given system. If we were to place users' actions on the arrows between the web pages in the site map we would have a state transition chart. A common way to represent users' input is to use state transition charts. In such charts, every node represents a state in the input sequence at which the user can pause or make a choice. The nodes are linked together in a directed graph by placing arrows between the nodes. Labels placed on each arrow (or arc) represent the action performed by the user and the result of that action. A major drawback of these charts is that they become very difficult to read and draw as the system becomes more complex (Newman \& Lamming, 1995).

State transitions, however, are not only used to describe input. They are also used to describe system output. One form such charts can take is Object State Transition Charts, also known as OSTCs or 'ostrich charts' (Newman \& Lamming, 1995). These charts depict the state of the user interface objects in nodes, while users' actions are depicted using labelled arrows between the states.

Storyboards are visual scenarios telling a story. First developed by moviemakers trying to illustrate their manuscripts, they are closely related to, and often make use of, the visual language of comics. Here the states of the story are expressed in frames and readers have to infer what happens between the frames. Sketching in interaction design tends to take the form of storyboards, where arrows are used to express movements and transitions. This fact has led several research teams to develop computer tools for storyboarding. Examples include Silk (Landay \& Myers, 1995) Cross- Weaver (Sinha \& Landay, 2001), Anecdote (Harada et al., 1996), Denim (Lin et al., 2000), and Demais (Bailey \& Konstan, 2003; Bailey et al., 2001).

\section{Planned enactments}

By enacting the role of users and system components, a designer can better figure out how an interactive system should behave and appear to the user. One of the key techniques, in the creativity technique called synectics, is personal analogies: participants are encouraged to imagine what it would be like to be the system or a component of the system (Cross, 2000). For example, what would it feel like to be the garbage collector in the programming environment of LISP? In fact, enactment, where a person acts out the performance of someone else or animates the behaviour of an object has been argued to be vital in design (Tang, 1989; Robertson, 1996, 1997). The enactment allows a designer to create and take part in a timebased representation of an activity, and others can join in this enactment.
Similar enactments, but for a different purpose, are used in low-fidelity paper prototype sessions. In such sessions the aim is to do user testing of a system that is represented on paper. One person takes on the role of the computer during the session; this person displays the feedback from the computer to the user by moving pieces of paper and providing sound feedback (Snyder, 2003). The purpose is to test the design by simulating to the user how the computer would behave.

Enactments can also be used to test how the user would behave. Jeff Hawkins, the inventor of PalmPilot, has been said to walk around with small pieces of wood in his pocket to prototype a PDA (personal digital assistant) and discover where and when he could make use of the product (Sato \& Salvador, 1999). Buchenau \& Suri (2000) describe this kind of prototyping as "experience prototyping"; they highlight "the experiential aspect of whatever representations are needed to successfully (re)live or convey an experience with a product, space or system" (p. 424). The idea is for the individual to experience it personally rather than watching a demonstration or someone else's experience. If they are to experience the technology personally, designers must actively experience the subtle differences between design alternatives, and explore by doing. Buchenau \& Sari say that doing so will make it easier to grasp issues and feel empathy with stakeholders and their experiences. Thus, designers can explore by asking questions such as "what would it feel like if ...?"

In participatory design, developers sometimes engage users, employing staged and planned performances and role play in order to try out prototypes and mockups. Their aim is to explore usage situations in a highly engaged way and to develop empathy. These performances can take the form of improvisational theatre or staged scenarios (lacucci et al., 2000; Eden et al., 2002; lacucci et al., 2002; Howard et al., 2002).

\section{Situated enactments}

The above techniques for acting out interaction are all planned and structured. Other enactments, however, are unplanned, situated, and taken for granted. These expressions of the dynamics of interaction and usage often take the form of gesture.

Designers frequently use hand gestures to make references (Fleming, 1998). This includes pointing to make references and gesturing to clarify or emphasize concepts (e.g. shrinking a square with the hands while asking "or can we scale the size down?"). Gestures form an important part of the spatial-action language of designers and making gestures is a convenient way to express the behaviour of both users and objects (Tang, 1989; Robertson, 1996; Athavankar, 1999; Hummels, 2000). These gestural enactments are sometimes made in relation to a text or a sketch. In themselves, gestures and hypothetical user actions are ephemeral, and do not leave stable representations for future scrutiny (Tuikka, 2002). Performing sequences of collaborative enactments is one way to explore ideas and share knowledge (Wulff et al., 1990; Bekker et al., 1995). They create a lived experience for the actor that also can be seen and assessed by others. This helps the design team focus on what the user is doing at all stages in the design (Robertson, 1996). 
For example, Bekker et al. (1995) describe how designers illustrate how customers at an automatic post office placed packages on a scale, punching in numbers and sticking postage stickers onto the box, before putting the box in the bin. Using gestures, they illustrated opening and closing of doors and other actions, and often moved around while gesturing. The gestures occurred in relation to the spatial arrangements of the participants and work objects, and some gestures persisted throughout the meeting, even though they referred to imaginary objects.

In analyses of cognitive practices, it has been shown that gestures can be a means of mapping the invisible and untouchable to concrete experiences. A sketch makes an abstract idea of, for example, user behaviour or product operations more concrete, and a gesture is made in reference to this static representation. Then the once-abstract object becomes dynamic as it is construed as being in motion. People use gesture to enhance the embodied experience of a representation. Bodily engagement can be used to reason about how two static representations are related to each other. In such a process, gesture often ties together different representations into larger schematic units, marking out potential dependencies between representations. (Alač \& Hutchins, 2004)

When people try to understand a dynamic process, they frequently make referential displacements, where they personalize inanimate objects (0chs et al., 1996). Graphic representations then provide a cognitive and spatial domain to inhabit and move around in. By using gestures in a graphic space people can symbolically re-enact events in front of each other in a collaborative thinkingthrough process.

Graphical representations play a key role in such a process, in that they can be treated as stages on which people can collaboratively dramatize their understanding. In these dramatizations one team member may in fact act as choreographer for another team member's enactment (Ochs et al., 1994).

Based on previous research which has indicated that kinetic gestures and enactment play an important role in exploring how a product is used (Tang, 1989; Wulff et al., 1990; Bekker et al., 1995; Robertson, 1996, 1997; Athavankar, 1999; Hummels, 2000; Tuikka, 2002), we decided to analyse what it is that interaction designers are enacting with their kinetic gestures. In this analysis we also draw on discussions from practice studies of cognitive activity (Alac \& Hutchins, 2004; Ochs, 1994, 1996).

\section{Domains in interaction design}

To analyse what it is that interaction designers express with kinetic gestures, we developed a model built on the idea of interaction design as being performed in several domains at different levels of detail. Several models of interaction design conceptualize different levels of detail. One can, for example, think of the object for interaction design in terms of the three levels from activity theory: activity, action, and operations (Arvola, 2005). Van Welie \& van der Veer (2003) suggest interaction design patterns at the levels of business goals, posture, user experience, task, and action.
Design patterns have also been thought of at the levels of environments for interaction, means for interaction, and interfaces for interaction (Arvola, 2006).

The domains we use in this article divide up the design space slightly differently compared with the models presented above. We draw on information design as well as architecture (Woolman, 2002) and expand on the process of interactive design as described by Kristof \& Satran (1995). Our model includes the five elements of design concept, function and content, structure, interaction, and presentation.

- Design conceptcan be thought of as the design idea in terms of its purpose and intended use. This is what the product should do and be; it includes the definition of its audience and users. The character of the system (Arvola, 2003, 2005), the dynamic gestalt (Löwgren \& Stolterman, 2004), the genre (Lundberg, 2005), and the posture (Cooper et al., 2003; vanWelie $\&$ van der Veer, 2003) are all elements of the design concept.

- Function and content are the functions and the information content needed to fulfil the purpose and intended use of the design concept. This is equivalent to the object-action model of the system (e.g. Shneiderman \& Plaisant, 2004).

- Structure is the arrangement and organization of functions and content. The structure can be flat or deep. It can be hierarchical, networked, linear, or circular. Things like task structures, flow charts, and site maps belong to this domain.

- Interaction is how the user interacts with the functions and contents and how he or she navigates in the structure to make use of functions, access or manipulate content, and fulfil the intended use. Interaction styles such as forms, menus, and direct manipulation, and interaction techniques such as zooming, panning, and point-and-click, as well as controls and interaction devices, are all parameters of this domain.

- Presentation is the look and feel of the product. This is what meets the senses of the user and this is what needs to be interpreted in the situation of use. This is the graphical part of a graphical user interface. Issues of style and layout become important here.

The five domains described above can be thought of as being at different levels of detail in the interactive system that is being designed. In this paper, we use them to analyse what the interaction designers are expressing and enacting in their kinetic gestures.

\section{METHOD}

This study reports a detailed analysis of a fourhour design workshop with four master's students in interaction design. This particular workshop is part of a series of workshops with students performing and learning interaction design. In total, the empirical material is encompassed by approximately 20 hours of video recordings made using multiple cameras. 
Our studies took place at the Royal Institute of Technology in Kista where an interactive space called the iLounge was designed and built with the purpose of supporting colocated collaborative work. It is used both as a learning facility and as an experimental research facility. Two large touch-sensitive displays (smartboards) are built into a wall. In front of this wall is a table with a horizontally embedded plasma screen, also touch-sensitive. This interactive table is large enough for up to eight people to sit round it. In one corner of the room a smaller table and three chairs are placed in front of a wall-mounted plasma display, enabling a part of the group to work separately. Figure 1 shows a plan of the room. The room has a wireless network and contains laptop computers with a wireless LAN card. The keyboards and mice in the room are also wireless, using Bluetooth. Finally, the iLounge contains high-quality audio and video equipment that can be used for videoconferences, or during user studies.

Because there are many computers in the room and users can also bring their personal artefacts into the room, it is not at all obvious how information is shared between the different work surfaces. To facilitate and support work in the iLounge most research so far has focused on developing services that support the user in moving data between the devices present in the room. Tipple ${ }^{1}$ is a service that can be used to open any file on any other computer that runs the Tipple service. Its interface shows icons representing all the other computers running the service. A user who wants to open a file on another computer can drag the file icon to the icon representing the other computer; an early prototype is described in Werle et al. (2001). The service Multibrowse allows the user to move web content between displays in the room. By right-clicking a page or a link, a user can "multibrowse" it either to or from its present location; see Johanson et al. (2001) for a more thorough description. PointRight makes it possible to use the same pointing device or keyboard on more than one computer in the room. When the pointer reaches the border of the screen it continues on the screen next to it that also has the service. By using PointRight together with iClipboard, a user can cut or copy text between computers in the space. The text is placed on a clipboard that is shared by the computers running the service. ${ }^{2}$

In the study reported on in this paper we also introduced some Smart Technologies services to the participants, specifically the virtual keyboard and Smart Notebook. Smart Notebook is an electronic whiteboard application that allows the user to create documents containing typed text, hand-written text, and pictures. The document is visualized as a book with pages.

\section{Procedure}

Four master's students in interaction design, two male and two female, were invited to iLounge. They all knew each other well, having taken the same courses for four years. The two female students were given a design brief asking them to design an interactive space to be used for studio classes. The two male students were given a brief asking them to design a drawing tool for an interactive digital whiteboard. The briefs thus pointed towards design solutions in the direction of the iLounge they were to visit

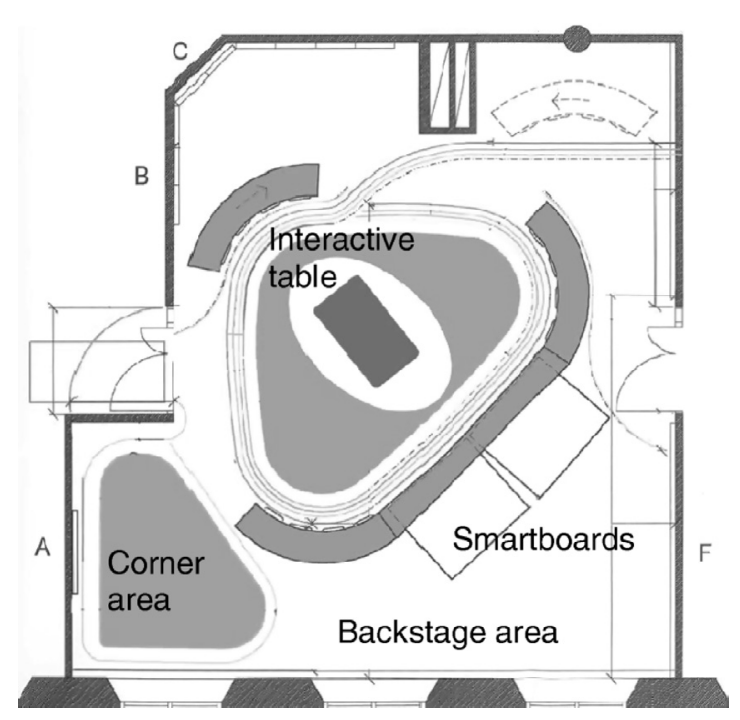

Figure1.

Blueprint of the room.

and experience. Our idea was that they were to seriously consider how they would like such an environment to be structured, and thus come up with ideas about how iLounge could be improved.

The participants had worked individually on their designs before coming to iLounge. During the visit to iLounge they synthesized their individual design work with the work of the other design student who had been given the same brief. They then presented their collective ideas to the two other students and ran a critique session. After these sessions we conducted an evaluation of the iLounge studio and what they thought about working there. During the first hour, an introduction to iLounge was given. Each group then took about 30 minutes each to synthesize their designs and about 10 minutes to present their ideas; the critique session took about 115 minutes for each pair. The evaluation was performed during the following hour.

We recorded all sessions using both audio and video from multiple cameras. No interventions were made during the sessions, except during the evaluation, which was facilitated.

\section{Analysis}

After we gathered the data, we analysed it together. The focus of our analysis was on the gestures and dramatizations (i.e. enactments) of their design proposals. During the analysis we interpreted the enactments and their performatives. We also traced our interpretations of events in the synthesis sessions to events in the presentation sessions.

All verbal utterances and gestures were transcribed in our native language (Swedish). We then analysed the transcriptions further as we engaged with them theoretically using previous research and the five domains of interaction design (design concept, functions \& content, structure, interaction, and presentation), and only then did we translate them into English. 


\section{RESULTS}

In this section we describe how the designers enacted their design sketches using gestures to make them behave. Often they incorporated these enactments within acts of speech but, as we shall see, the enactments had no signifying word or verbal counterpart during the sessions. The enactments enhanced what the designers wanted to communicate, much in the way that sketches provide simplified visualizations of a complex and dynamic design proposal. In this section we present examples of how such communicative enactments are performed and what domains of interaction design they represent.

\section{Gestures expressing interaction and design concept} The two women, whom we will call Anna and Barbara, had the assignment of designing an interactive space using different digital resources. They started their synthesis session by quickly examining their sketches and summarizing their basic ideas about an interactive space. They had two basic ideas: that users needed plenty of space for sketches and that they needed space for both individual and collective activities. They were quite surprised that their sketches coincided. One of them, Anna, quickly took on the role of sketching on the smartboard and Barbara took on being the discussant, structuring the process of synthesizing the design by suggesting themes and discussing individual design proposals as well as documenting ideas. Anna generally expressed herself using many gestures, while Barbara was more modest with her gestures.

Barbara suggested that to structure the process they should start off by sketching things that would not need to be mobile, "like whiteboards etc.". In Excerpt 1 we see how she was abruptly interrupted by Anna, who vividly presented an idea about a mobile whiteboard.

Although Barbara suggested starting off with non-mobile furniture the discussion then focused on Anna's idea of a mobile smartboard that can be tilted. By demonstrating how a smartboard can be slanted from a vertical to a horizontal position Anna enacted the interaction, which was closely connected to the purpose of their design concept. First, in turn 1, Anna waved her arms to act out how it should be possible to slant the smartboard, and in turn 3 , she made an act of seeing-as where the smartboards can be pulled along like a curtain. In turn 4, Barbara made a mirroring tilting gesture. In this gesture she both experienced the interaction of tilting the board, and affirmed that she understood the concept. They both found this idea very appealing. Anna, however, also considered the structure and construction of such an artefact.

In terms of the five domains of interaction design (design concept, functions \& content, structure, interaction, and presentation) the designers start out by expressing interaction in the gestural enactment (the tilting). They immediately see that there are consequences for the structural domain (how transmissions work), and the design concept (with the purpose of providing flexibility). In the next gestural enactment the see the smartboard as a curtain, and combine that with the tilting to make complex hypothetical user actions and object behaviour. Finally, they make the connection back again to the design concept domain by seeing that there are positive consequences (when Anna says, “Write: for different purposes").

About 15 minutes later, while they were discussing and summarizing their synthesized design proposal, they returned to the enactment of the tilting table. During the process they had said that they should denote different aspects of the properties in the room using different colours: blue was to denote technology. Excerpt 2 presents what they said and Figure 2 to Figure 7 depict the enactments in a picture sequence.

When Anna suggested that she draw the tables into their design sketch using the blue pen to denote technology, Barbara did not understand why the tables should be denoted in blue. This misunderstanding is reasonable as they had been discussing both tables in the sense of ordinary designed tables and an enacted "tilting" smartboard. When Barbara asked whether the tables counted as technology, Anna answered by again enacting the tilting table; this helped Barbara understand, and she then mirrored the tilting with her arms. They had still not given this table/board a name or label. The tilting table existed only in the enactment that the two designers shared.

\section{Gestures expressing interaction and presentation}

The two men, whom we will call Christian and Daniel, had the assignment of designing a drawing tool for a smartboard. Their synthesis session started directly, as they discussed differences between traditional whiteboards and a digital counterpart in terms of affordances. Christian went to the smartboard and started up the installed sketchpad, and then sat down to listen to Daniel. Daniel first explained his view of the differences in what it is possible to do with a traditional whiteboard. They both pointed to the object-centred character of the digital whiteboard (that the user works with drawn objects rather than with pen strokes). In excerpt 3 , we see how Daniel went to the smartboard and presented his idea about the differences. Figure 8 is embedded in the excerpt in order to put it in context.

Their preliminary and quite spontaneous analysis of the differences between traditional and digital whiteboards was clearly connected to their enactment of interaction. In fact, the enactments drove the analysis, moving it from an abstract and analytical perspective on the differences in affordances, to the concrete and physical behaviour of this actual digital whiteboard. By exploring this analysis of affordances at the same time that he explored the actual smartboard Daniel dramatized a type of user behaviour: a designer's thinkaloud exploration. This enactment also took place on the presentation level, since the designers explored the feel of the smartboard. In this case it did not feel natural. Christian, who was sitting down, was more distant in his attempts to take the floor but Daniel was so engaged in his exploratory dramatization that he seemed to more or less ignore Christian's initiatives. When Christian prompted Daniel to think about whether he had an alternative idea about interacting, the discussion ended with a blunt no, with Daniel's extension that maybe it could all have been done with a mouse. The exploratory dramatization might have made Daniel a bit disillusioned about how one can interact with the smartboard as he reverted to an almost mundane form of interaction. 


\begin{tabular}{|c|c|c|c|c|}
\hline Time 0.10.27 & Person & Transcript of interaction & $\begin{array}{l}\text { Characteristic } \\
\text { of action }\end{array}$ & Domain \\
\hline 1 & Anna & $\begin{array}{l}\text { Some of these come on small stands } \\
\text { with wheels. [Barbara: OK] It depends } \\
\text { on, I don't know, it depends on how the } \\
\text { transmission works, but if there are many } \\
\text { sockets then you can put it in different } \\
\text { places... or at least slant it so it depends } \\
\text { on if they are permanent like these or not. }\end{array}$ & $\begin{array}{l}\text { Stands up and vividly enacts } \\
\text { a "tilting table" with her } \\
\text { arms: Holds arms straight } \\
\text { out with one hand vertically } \\
\text { positioned under the other. } \\
\text { Moves hands in a curve } \\
\text { downwards so that they } \\
\text { are horizontally positioned } \\
\text { in regard to each other. } \\
\text { (See Figures } 27 \text { below for a } \\
\text { similar enactment later in the } \\
\text { conversation.) }\end{array}$ & $\begin{array}{l}\text { Interaction, } \\
\text { Structure, } \\
\text { Design } \\
\text { concept }\end{array}$ \\
\hline 2 & Barbara & For the whiteboard then ... & $\begin{array}{l}\text { Sits down and documents } \\
\text { some of the ideas they have } \\
\text { suggested. }\end{array}$ & Interaction \\
\hline 3 & Anna & $\begin{array}{l}\text { Yes, like those old stands like those old } \\
\text { rolling blackboards [Barbara: uh huh, OK] } \\
\text { that you could move like a curtain at the } \\
\text { theatre. }\end{array}$ & $\begin{array}{l}\text { While saying, "curtain at the } \\
\text { theatre," she walks as if she } \\
\text { is pulling the curtain. }\end{array}$ & \\
\hline 4 & Barbara & Could you make them work that way too? & $\begin{array}{l}\text { She makes a gesture } \\
\text { indicating a table that can be } \\
\text { tilted. }\end{array}$ & Interaction \\
\hline 5 & Anna & I don't know, but it would be cool. & & \\
\hline 6 & Barbara & $\begin{array}{l}\text { It would be cool [writes] I'll write work } \\
\text { area. }\end{array}$ & $\begin{array}{l}\text { Documenting some of the } \\
\text { discussion. }\end{array}$ & \\
\hline 7 & Anna & Write: for different purposes. & & $\begin{array}{l}\text { Design } \\
\text { concept }\end{array}$ \\
\hline
\end{tabular}

Excerpt 1.

Group 1, Synthesis session. The tilting table ${ }^{3}$

Turning to the five domains of interaction design, we see that the gestural enactment here also started in the domain of interaction, and this time the designers were seeing that it had consequences for the presentation (it did not feel natural).

\section{Improvised role play expressing design concept} In the following excerpt we exemplify how the two male designers explored the different uses of the actual smartboards in order to design them to be used for collaborative purposes. It is striking that the pair started to dramatize their work using other voices, as if to express explicitly that someone else (the user) would say and act out what they think. These forms of voice dramatization quickly turned into examples of what each speaker wanted to do. In turn, the two amplified and enhanced these examples as they engaged in enactments, trying to do what they anticipated the users doing (see Excerpt 4). Here Daniel concluded by describing the concept of the traditional whiteboard. Figure 9 depicts the two designers taking on the role of the users.

\begin{tabular}{llll} 
Time 0.18.36 & Person & Transcript of interaction & $\begin{array}{l}\text { Characteristic } \\
\text { of action }\end{array}$ \\
\hline 1 & Anna & $\begin{array}{l}\text { Okay, but then I'll draw them in blue as } \\
\text { they are technology. }\end{array}$ & $\begin{array}{l}\text { Reaches for the smartboard } \\
\text { pen and moves towards the } \\
\text { smartboard. }\end{array}$ \\
2 & Barbara & The tables? Are they technology? & $\begin{array}{l}\text { Physically represents a tilting } \\
\text { table (Figures 2-5) } \\
3\end{array}$ \\
Anna & Well ... the ... & $\begin{array}{l}\text { Mirrors the enactment } \\
\text { (Figures 5-7) }\end{array}$ \\
\hline
\end{tabular}

Excerpt 2.

Group 1, Synthesis session. The tilting table, continued 

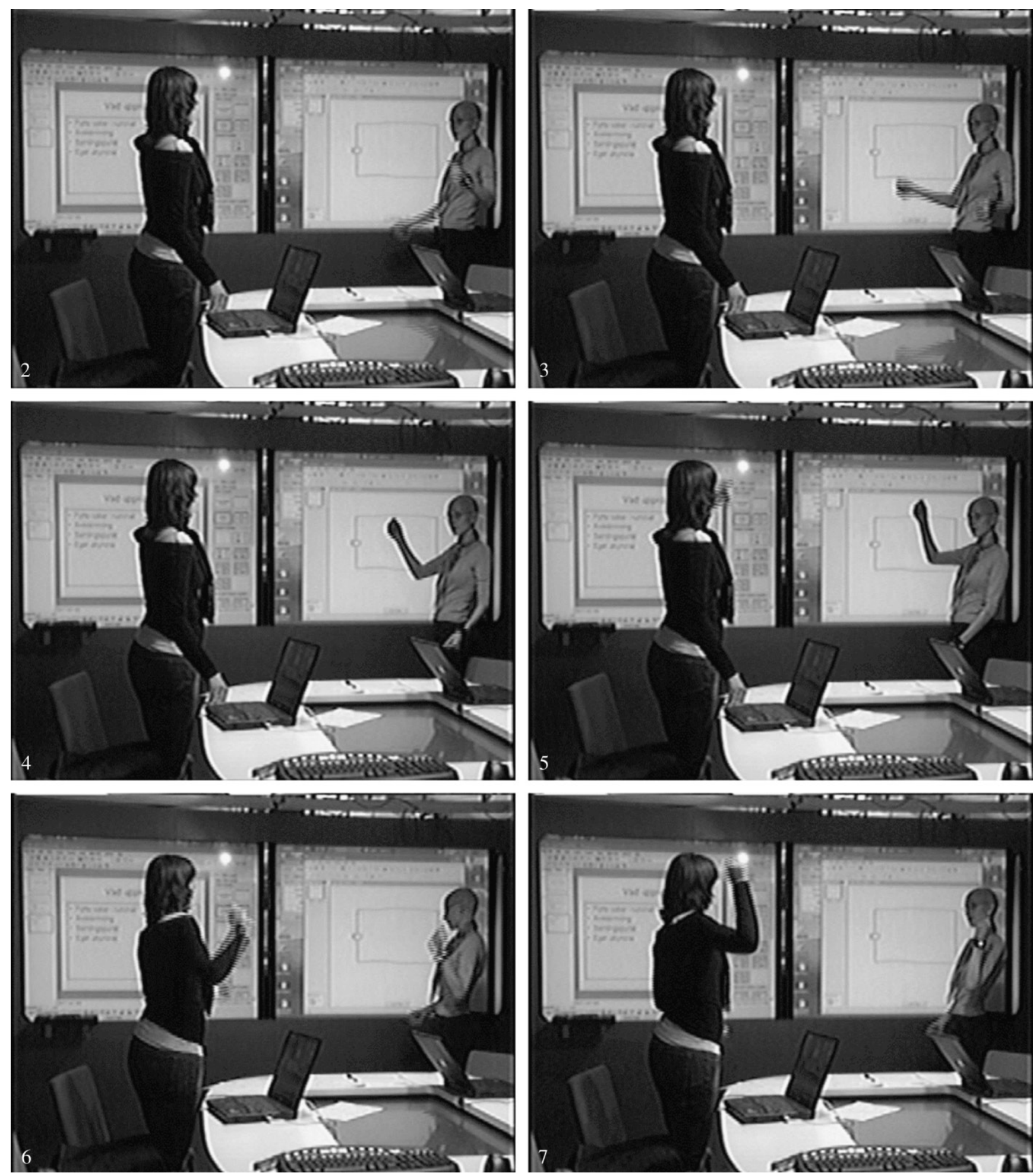

Figures 2-7. Sequence showing the enactment of "the tilting table".

In Figures 2-5, Anna waves her arms to enact "the tilting table" and in Figures 6 and 7, Barbara mirrors the enactment.

This episode of dramatization is interesting in that both designers cooperated in the drama; Christian followed Daniel, playing along with his initiatives. In the earlier excerpts, we also saw that the female designers were playing along but they mirrored each other's enactments rather than one taking a distinct lead. In this session the two designers cooperate and play along, using both gestures and voice in taking on the roles of users. These short role-playing sessions evolve into a discussion of what target context the user would be in. They explore the concept of cooperative sketching by role playing. Again, this can be analysed using the five domains of interaction design. This time, the enactment does not start in the domain of interaction. Instead it starts in the domain of the design concept: the need to be able to work at the same time. In their enactment they continue by moving from the domain of design concept to the domain of functions and content (when they 


\begin{tabular}{|c|c|c|c|c|}
\hline 1 & Daniel & $\begin{array}{l}\text { Because when you .... When you draw then .... } \\
\text { you know, this is not natura ... it's not natural. I } \\
\text { must put this pen away then take my finger and } \\
\text { drag this. You know, I do this only because I know I } \\
\text { can put away the pen and use my finger as a mouse } \\
\text { so to speak [\#1:yes] }\end{array}$ & & $\begin{array}{l}\text { Interaction, } \\
\text { Presentation }\end{array}$ \\
\hline 2 & Christian & But at the same time I think that it's like ... & & \\
\hline 3 & Daniel & But it's good that you can do that as if it is an object & $\begin{array}{l}\text { Continues to } \\
\text { demonstrate how } \\
\text { users would behave }\end{array}$ & Interaction \\
\hline 4 & Christian & Did you have any alernative, or & & \\
\hline 5 & Daniel & $\begin{array}{l}\text { No, not really, l just thought that you might have a } \\
\text { tool to use? As a mouse... }\end{array}$ & & Interaction \\
\hline
\end{tabular}

Excerpt 3.

Group 2, Synthesis session. Naturally not natural.

identify functions such as move and draw). In the next moment they have seen consequences in the domain of structure (one person works in one corner while the other works in the other corner). At this stage they see the benefit of the whiteboard, at which point they are back in the domain of the design concept.

After this episode, Christian started a long enactment of a scenario involving several users using the same smartsketching whiteboard. A while later, the pair turned to a discussion of how the technology could cope with several users, the functions it would require, and how it should be structured and constructed.

\section{Improvised role play to discover consequences} While they were playing around with the actual smartboard, the two male designers discovered that it handled objects and sketches differently. These are two different kinds of content, created using different functions. Sketches made with the pencil can easily be deleted with an eraser, while geometric objects (rectangles, circles etc.) cannot be erased with the eraser but have to be deleted using the menus. The designers saw this as a serious problem, one they discussed thoroughly in their final design presentation. In Figure 10 , we see Daniel that enacts how he would erase an object using a smartboard eraser but he fails, because it is an object rather than a free-hand sketch. Here, the enactment starts out in the domain of functions (easing vs. deleting) and content (free-hand sketches vs. objects).

This discovery reminded them that they were not to evaluate the current system but rather to design a system to support collaborative design tasks. They started to summarize this process in Excerpt 5, which provides further examples of their collaborative thinking- through process.

During this excerpt they continued to try out the design proposals. In contrast to earlier excerpts we see that earlier enactments of hypothetical user activity have consequences in the domain of structure (how functions and content should be organized technically, temporally, and spatially). Christian enacts the parallel work, which

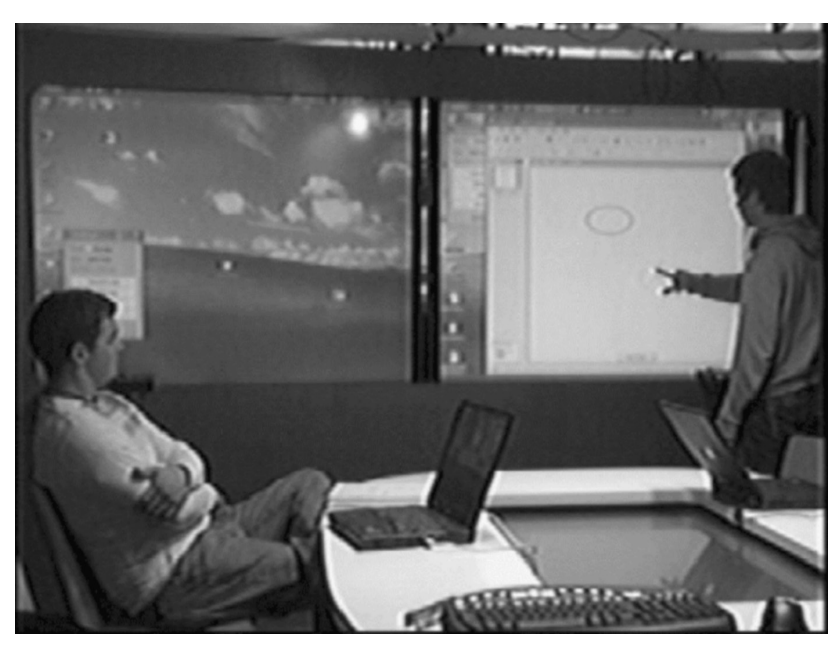

Figure 8.

Presents his argument by making a sketch of how one does not do it naturally.

is part of the design concept, in order to demonstrate the benefit of the proposed structure. During this enactment he also discovers the need for new functionality (identification of users).

Christian was active, talking and exemplifying using enactments, while Daniel did a lot of backchannelling (which has not been transcribed fully) as well as trying to document and play around with some sketches (Figure 11). The progression of their design ideas correlated well with their own experiences and uses of the technology. Thus their experiences of using the smartboard, as well as their experiences of playing at being users with the existing smartboard, drove the discussion forward. After this session they refined the sketch (Figure 12).

\section{DISCUSSION}

We began this paper with an overarching problem: how interaction designers express the dynamics of interaction. Looking at previous research as well as our results, we have seen that they create the dynamic 


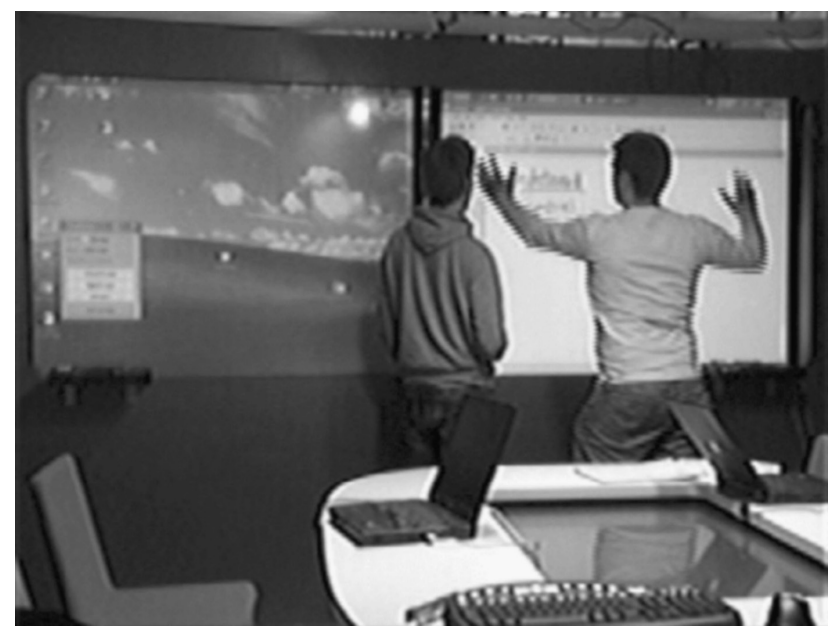

Figure 9.

Both designers are working together in vividly dramatizing the users' behaviours.

aspects within a tight coupling of talk, graphical representations, and gestural enactments.

The sketches are important as tools for thought but it is the enactments and dramatizations that make the sketches behave. Playing the role of a user, and exploring the potential technology with the intent of using it, helps designers explore the design and their design ideas, and also come up with new ideas.

The enactments help designers to focus and move themselves imaginatively into the target context where their design solution might be used. As such, gestures serve as a powerful means to collaboratively assess the use of their design and engage in the situation of its use (see also Robertson, 1996, 1997; Tuikka, 2002). But gestures do not only help designers assume the role of the user. They also help them take on the role of the artefactin-use. In the empirical material, we saw how Christian and Daniel constantly imagined and enacted what the computer should be doing; for example, how it should behave when the eraser was applied to an object.

In the action context of the here and now, designers speak, gesture, and modify graphic representations. The graphic representations create a space, representing the target context, in which designers can perform design moves (Artman et al., 2005). They do so by continuously modifying the graphic representations and by performing gestural enactments to communicate and explore the dynamics of interaction. This process supports the interaction designers in imagining themselves as part of the interaction processes of people and artefacts. Our observations support the work by Robertson $(1996,1997)$ who describes how designers use enactments to create and take part in a time-based representation of process or activity that others can take part in (see also 0 chs et al., 1994, 1996).

Sketches can be thought of as states in a state diagram; what the diagram lacks is the transitions. In order to represent the transitions between states, the designers make use of gestures. In fact, the tilting table has two states: horizontal and vertical. In between those

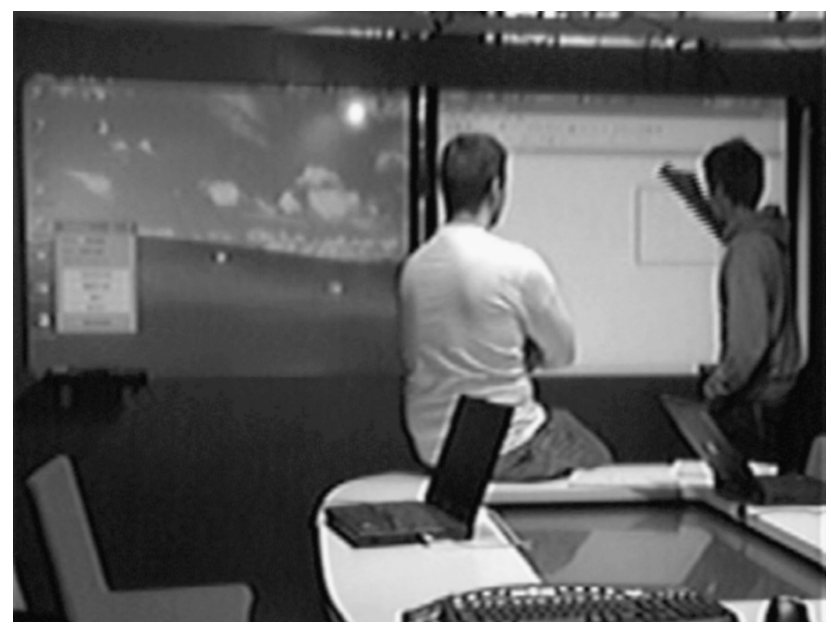

Figure 10.

Daniel is trying to demonstratively erase an object, saying "This is all wrong".

states there is a transition, which the women designers represented by using arm movements. Similarly, as Christian and Daniel dramatized the users' utterances and actions, they were representing transitions within and between functions, thus creating and experiencing structure and interaction. This can be seen as a form of experience prototyping (Buchenau \& Suri, 2000). The drama becomes a process of collaborative reasoning, firmly anchored in a situation of imagined use. Once again, this echoes the research by Tang (1989), Robertson $(1996,1997)$, Tuikka (2002), Alac \& Hutchins (2004) and Ochs et al. $(1994,1996)$. We think that early in their training designers must learn to acknowledge and even articulate these enactments as important ways to express themselves as they develop designs. This is especially important since much of the design in industrial settings is accomplished in joint collaboration in front of whiteboards (Lantz et al., 2005).

\section{Enactments and domains of interaction design}

Let us now turn to our model with five domains of interaction design (design concept, functions \& content, structure, interaction, and presentation). We set out to analyse what it is that is expressed in kinetic gestures and enactments in more detail using this model.

In Excerpts 1, 2, and 3 the participants perform their enactments using gestures that mimic the actions of users in an interaction walkthrough. The interaction walkthrough is a gesture-driven enactment. In Excerpts 4 and 5 Christian and Daniel takes on the role of two users and imagine themselves in a certain situation of use. This improvised role play is a scenario-driven enactment, and is used as a designer's think-aloud exploration. Turning to the five domains of interaction design we see that the gesture-driven interaction walkthroughs started out from the domain of interaction and drove the designers to see that there were consequences for primarily the domain of presentation and the domain of design concept. There are also secondary consequences for the other domains. The enactments in the form of improvised role play started out from the domain of design concept (in terms of need and purpose) and propagated consequences primarily for the domain of functions and content, and the domain of 

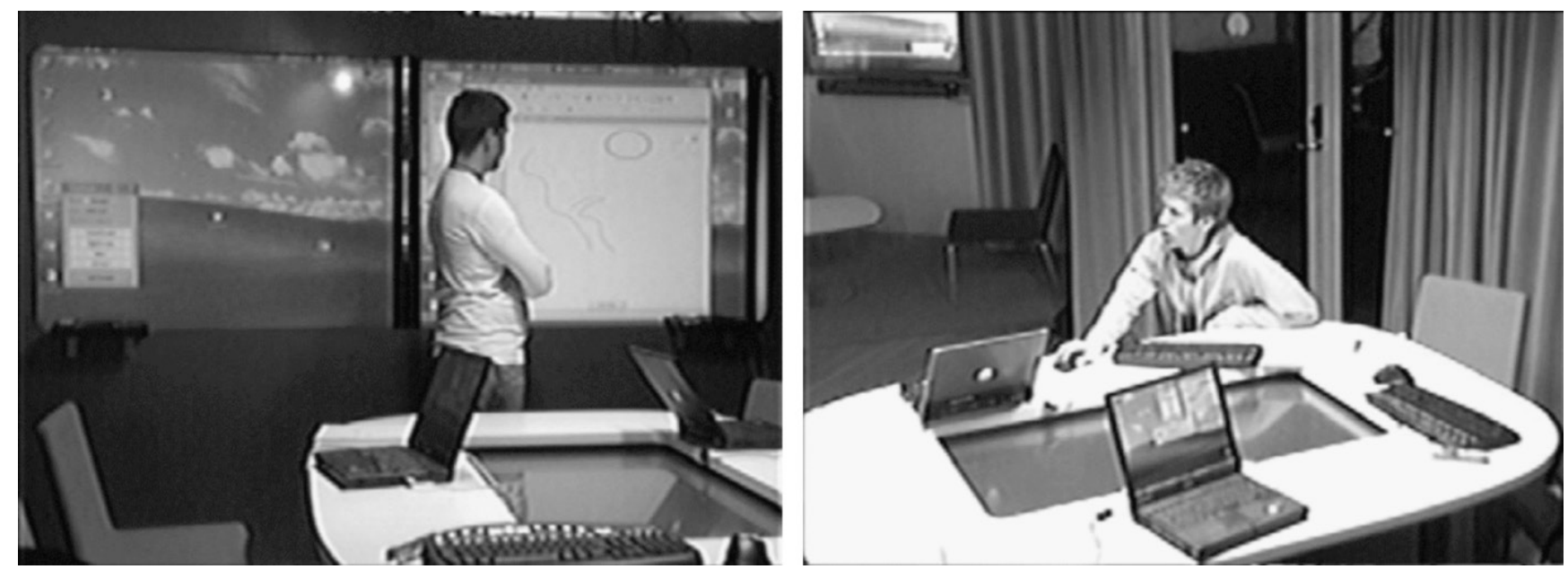

Figure 11.

Christian sums up the discussion and Daniel documents it through sketches and words.

structure. Secondarily, there are also consequences for the other domains.

Using interaction walkthroughs, driven by gestures, a means of expression gives the interaction designer expressive ability in the domains of interaction and presentation. It also facilitates seeing that there are consequences in the other domains. An example of that is when Anna and Barbara get the ideas of the functions tilt and pull based on their interaction walkthrough. These functions are also a specification of the concept of their mobile and flexible smartboards.

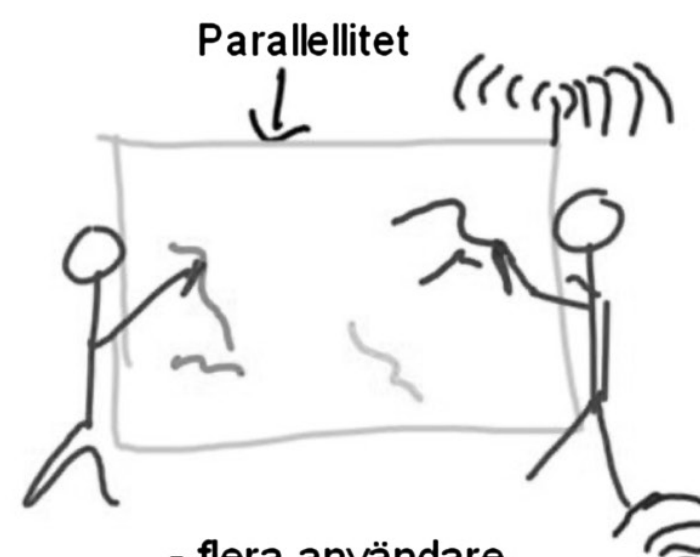

\section{Multimodal}

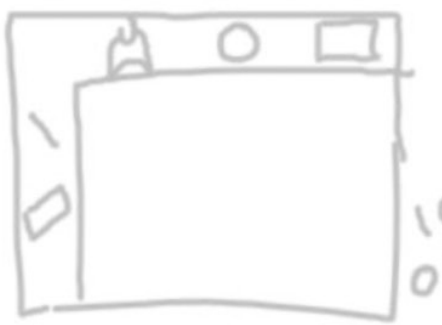

- Olika vyer beroende på modalitet (dator, whiteboard, handdator)

\section{- flera användare jobbar samtidigt}
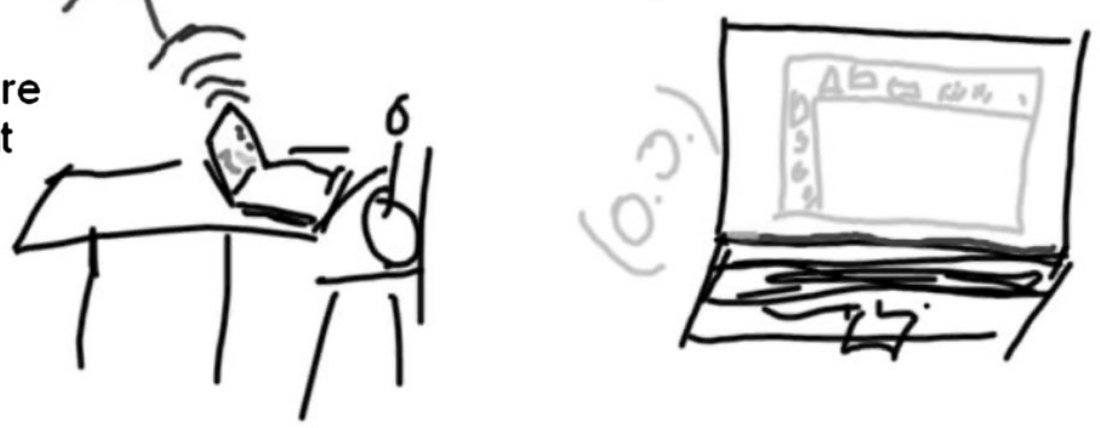

Figure 12.

Final sketch for presentation. Translation of the text in the sketch: Parallelism Several users work at the same time. Multimodal Different views depending on modality (computer, whiteboard, handheld computer). The "icke 0.0 ." means that whiteboard is not object oriented, while the application on the laptop is. 
Embodied enactments in interaction design are important for all domains of interaction design. Without these forms of expression, it would be difficult to express interaction and also the fundamental design concept. This would have consequences for the other domains: functions \& content, structure, and presentation.

\section{Future research}

As Tuikka (2002) has noted, enactments are of an ephemeral nature. This means that there are no stable traces of them. In order to make specifications for construction and to support asynchronous communication it is, however, necessary to document the dynamics in some way other than gestures and role play. Hummels (2000) provides examples of how arrows in sketches are used for that purpose. Improvised role play can be documented in high-level storyboards and written scenarios. Interaction walkthroughs can be documented in storyboards and state transition charts. Building running prototypes is probably an even better specification. No stable representations are, however, as swiftly used and convenient in collaborative design as enactments are, in the form of improvised role play and interaction walkthroughs. The communication between designers and systems developers is an area that largely has been neglected in research to date.

The use of gestural enactments points towards prototyping tools for interaction design that are built on principles of programming by example. Perhaps they could be used in combination with a gesture-based user interface (Landay \& Myers, 1995; Hummels, 2000). How to implement this kind of prototyping tool remains an issue for future research.

This study was carried out focusing on four master's students. To form a solid basis further research needs to be conducted. At the time of writing we have begun to expand the analysis to professional interaction designers in realworld design work. The interplay betweens means of expression will be studied particularly, as well as processes of learning how to use different means of expression.

\section{CONCLUSIONS}

In this paper, we have analysed what gestures in interaction design express. We have identified two means of expression of the dynamic aspects of interaction design: interaction walkthrough and improvised role play. Gestures drive the interaction walkthrough and scenarios created on the spot drive the improvised role play. These means of expression are two kinds of enactments that previous research has not distinguished between. In our analysis, based on our model of interaction design consisting of five domains (design concept, functions \& content, structure, interaction, and presentation), we have seen that interaction walkthroughs start out in the domain of interaction, and improvised role play starts out in the domain of design concept. From these domains the designer can then see consequences for the other domains. Given the ephemeral nature of enactments, the improvised role play and interaction walkthroughs still need to be documented in stable representations. Storyboards, scenarios, and state transition charts are examples of stable representations that can be used. We wish to conclude by emphasizing the implications for interaction design education. In this article we have seen the importance of two forms of enactment (improvised role play and interaction walkthroughs). These are means for expressions that can be used deliberately and reflectively by interaction designers. We think that education in interaction design must not only focus on the practice and skill of sketching but also acknowledge the natural and spontaneous enactment that represents dynamics.

\begin{tabular}{|c|c|c|c|c|}
\hline Time 0.05 .40 & Person & Transcript of interaction & $\begin{array}{l}\text { Characteristic } \\
\text { of action }\end{array}$ & Domain \\
\hline 1 & Daniel & $\begin{array}{l}\text { But I think it's, what I think is a bit difficult } \\
\text { about this is that we absolutely cannot } \\
\text { work at the same time. Think of if I were } \\
\text { to, like, "But check this out, then we } \\
\text { cannot have that there..." }\end{array}$ & & $\begin{array}{l}\text { Design } \\
\text { concept }\end{array}$ \\
\hline 2 & Christian & $\begin{array}{l}\text { Exactly. If we do that then I would come } \\
\text { and say, "But this should be here", but } \\
\text { you will say "No, it should be here". }\end{array}$ & & \\
\hline 3 & Daniel & $\begin{array}{l}\text { "But, we do like this" ... hang on ... wait } \\
\text { a moment. . }\end{array}$ & & \\
\hline 4 & Christian & $\begin{array}{l}\text { Then I want to at the same time, and want } \\
\text { to move these... }\end{array}$ & & $\begin{array}{l}\text { Functions \& } \\
\text { content }\end{array}$ \\
\hline 5 & Daniel & $\begin{array}{l}\text { Exactly ... or you want to draw .... } \\
\text { Say you want to draw down in the corner } \\
\ldots\end{array}$ & & Structure \\
\hline 6 & Christian & $\begin{array}{l}\text { There you have the advantage with the } \\
\text { whiteboard. Okay, then you sketch there } \\
\text { and I sketch here... }\end{array}$ & $\begin{array}{l}\text { Starts enacting several } \\
\text { scenarios of this collective } \\
\text { sketching situation. }\end{array}$ & $\begin{array}{l}\text { Design } \\
\text { concept }\end{array}$ \\
\hline
\end{tabular}

Excerpt 4.

Group 2, Synthesis session. You sketch there and I sketch here. 


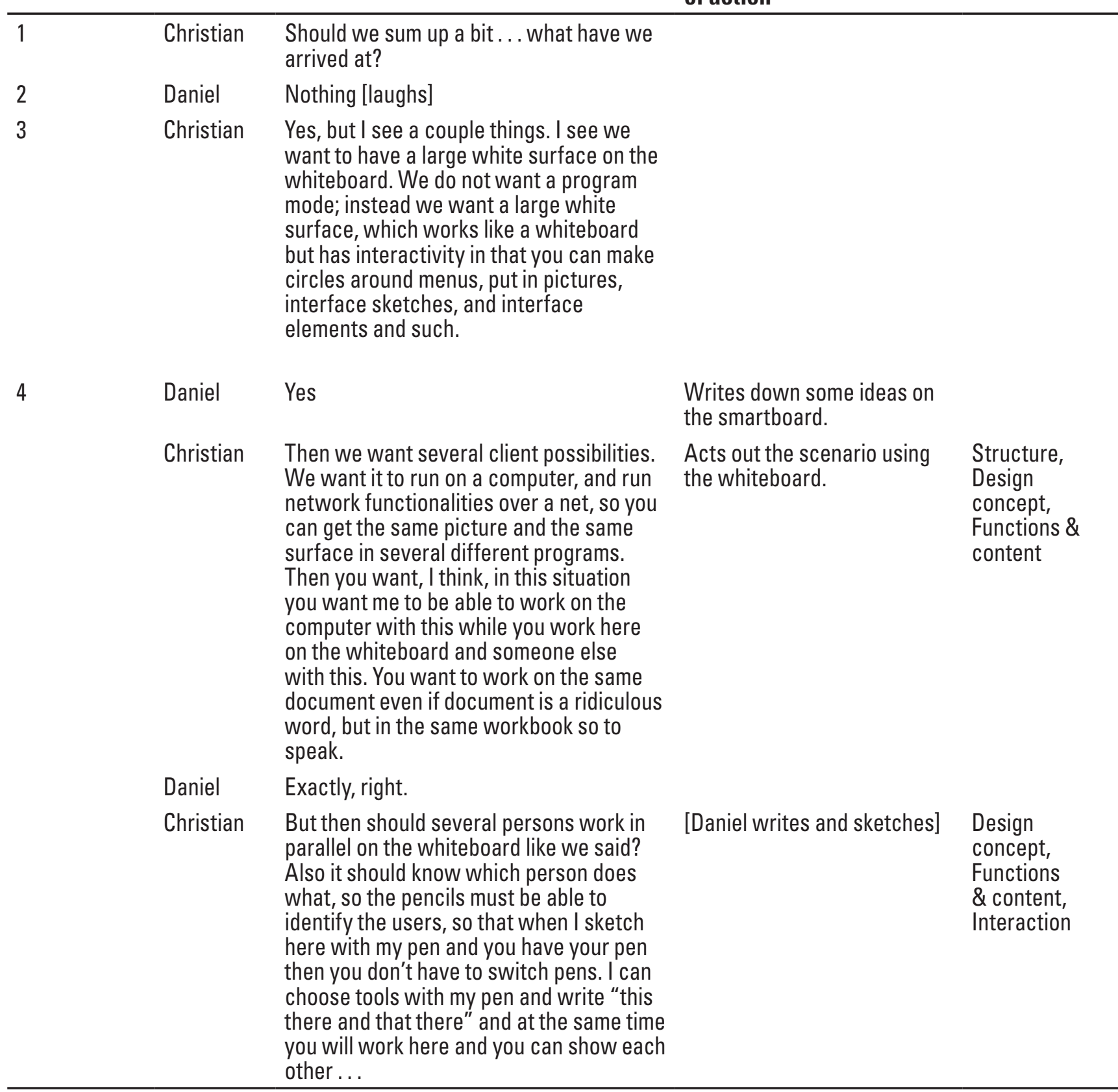

Excerpt 5.

Group 2; Synthesis session 3:2: Shall we sum up?

Our results imply that improvised role play and interaction walkthrough can be articulated as conscious means of expression to be taught and refined in the learning of interaction design. The model of design domains in interaction design (design concept, functions \& content, structure, interaction, and presentation) can be used to analyse and reflect thoughtfully on complex consequences of a design solution. This is useful for creating both a reflective learning practice and a reflective professional practice in interaction design.

\section{ACKNOWLEDGEMENTS}

The authors would like to thank Ann Lantz and Jonas Lundberg for comments on an earlier draft. This study was financed by the Swedish Research Council and VINNOVA.

\section{NOTES}

1. Tipple is being developed by the FUSE group, Stockholm University/Royal Institute of Technology, and can be downloaded at: http://www.dsv.su.se/fuse/downloads.htm

2. Multibrowse, Pointright and iClipboard are part of the iWork package being developed by the Interactive Workspaces at Stanford University. The iWork services can be downloaded at: http://iwork.stanford.edu/download.shtml 
3. The transcriptions are divided following the work of Pomerantz \& Fehr (1997). In our study, however, "characteristic of action" describes the actor's action, not the abstraction of the utterances.

\section{REFERENCES}

Alač, M., \& Hutchins, E. (2004). I see what you are saying: Action as cognition in $\mathrm{fMRI}$ brain mapping practice. Journal of Cognition and Culture, 4(34), 629-661.

Artman, H., Ramberg, R., Sundholm, H., \& Cerratto Pargman, T. (2005). Action context and target context representations: A case study on collaborative design learning. In T. Koschman, D. Suthers, \& T. W. Chan (Eds.), Computer supported collaborative learning 2005: The next 10 years!. Mahwah, NJ: Lawrence Erlbaum.

Arvola, M. (2003). The interaction character of computers in colocated collaboration. In E. O'Neill, P. Palangue \& P. Johnson (Eds.), People and computers XVII: Designing for society (pp. 37-51). London: Springer-Verlag.

Arvola, M. (2005). Shades of use: The dynamics of interaction design for sociable use. Linköping Studies in Science and Technology, Dissertation No. 900. Linköping, Sweden: Linköpings universitet. Available at: http://urn.kb.se/ resolve?urn/urn:nbn:se:liu:diva-5019 (accessed 1 May 2006).

Arvola, M. (2006). Interaction design patterns for computers in sociable use. International Journal of Computer Applications in Technology, 25(2/3), 128-139.

Arvola, M., \& Artman, H. (2006). Interaction walkthroughs and improvised role play. In L. Feijs, S. Kyffin, \& B. Young (Eds.), Design and semantics of form and movement: DeSForM 2006 (pp. 42-51). Eindhoven: Koninklijke Philips Electronics N.V.

Athavankar, U. (1999). Gestures, mental imagery and spatial reasoning. In J. S. Gero, \& B. Tversky (Eds.), Visual and Spatial Reasoning in Design. Sydney, Australia: University of Sydney, Key Centre of Design Computing and Cognition.

Bailey, B. P. \& Konstan, J. A. (2003). Are informal tools better? Comparing DEMAIS, pencil and paper, and Authorware for early multimedia design. In Proceedings of the SIGCHI conference on human factors in computing systems (pp. 313-320). New York: ACM Press.

Bailey, B. P., Konstan, J. A. \& Carlis, J. V. (2001). DEMAIS: Designing multimedia applications with interactive storyboards. In Proceedings of the ninth ACM international conference on Multimedia (pp. 241-250). New York: ACM Press.

Bekker, M., Olson, J.S. \& Olson, G. M. (1995). Analysis of gestures in face-to-face design teams provides guidance for how to use groupware in design. In Proceedings of the conference on Designing interactive systems: processes, practices, methods, and techniques (pp. 157-166). New York: ACM Press.

Buchenau, M. \& Suri, J. F. (2000). Experience prototyping. In Proceedings of the conference on Designing interactive systems: processes, practices, methods, and techniques (pp. 424-433). New York: ACM Press.

Cooper, A., Reimann, R., Reimann, R. M., \& Dubberly, H. (2003). About face 2.0: The essentials of interaction design. Chichester: Wiley.

Cross, N. (2000). Engineering design methods: Strategies for product design (3rd ed). Chichester: Wiley.

Eden, H., Scharff, E. \& Hornecker, E. (2002). Multilevel design and role play: Experiences in assessing support for neighborhood participation in design. In Proceedings of the conference on Designing interactive systems: processes, practices, methods, and techniques (pp. 387-392). New York: ACM Press.

Fällman, D. (2003). In romance with the materials of mobile interaction: A phenomenological approach to the design of mobile information technology. Dissertation, Umeå University, Sweden.

Fleming, D. (1998). Design talk: Constructing the object in studio conversations. Design issues, 14(2), 41-62

Goldschmidt, G. (1991). The dialectics of sketching. Creativity Research Journal, 4(2), 123-143.

Harada, K., Tanaka, E., Ogawa, R. \& Hara, Y. (1996). Anecdote: A multimedia storyboarding system with seamless authoring support. In Proceedings of the Forth ACM international conference on Multimedia (pp. 341351). New York: ACM Press.

Howard, S., Carroll, J., Murphy, J. \& Peck, J. (2002). Using 'endowed props' in scenariobased design. In Proceedings of the second Nordic conference on Humancomputer interaction (pp. 1-10). New York: ACM Press.

Hummels, C. (2000). Gestural design tools: Prototypes, experiments and scenarios. Dissertation, Technische Universiteit Delft, Delft, The Netherlands.

Hutchins, E. (2005). Material anchors for conceptual blends. Journal of Pragmatics, 37(10), 1555-1577.

lacucci, G., lacucci, C. \& Kuutti, K. (2002). Imagining and experiencing in design: The role of performances. In Proceedings of the second Nordic conference on Humancomputer interaction (pp. 167-176). New York: ACM Press.

lacucci, G., Kuutti, K. \& Ranta, M. (2000). On the move with a magic thing: Role playing in concept design of mobile services and products. In Proceedings of the conference on Designing interactive systems: processes, practices, methods, and techniques (pp. 193-202). New York: ACM Press.

Johanson, B., Ponnekanti, S., Sengupta, C. \& Fox, A. (2001) Multibrowsing: Moving web content across multiple displays. In Proceedings of the 3rd international conference on Ubiquitous computing (pp. 346-353). London: Springer-Verlag.

Kristof, R., \& Satran, A. (1995). Interactivity by design: Creating and communicating with new media. Mountainview, CA: Adobe.

Landay, J. A. \& Myers, B. A. (1995). Interactive sketching for early stages of user interface design. In Proceedings of the SIGCHI conference on Human factors in computing systems (pp. 43-50). New York: ACM Press.

Lantz, A., Artman, H. \& Ramberg, R. (2005). Interaction design as experienced by practitioners. In Proceedings of the Nordic design research conference 2005. Available at: http://www.tii.se/ reform/inthemaking/proceedings.htm (accessed 1 May 2006).

Lin, J., Newman, M. W., Hong, J. I. \& Landay, J. A. (2000). DENIM: Finding a tighter fit between tools and practice for web site design. In Proceedings of the SIGCHI conference on Human factors in computing systems (pp. 510-517). New York: ACM Press.

Löwgren, J. (2004). Animated use sketches as design representations. Interactions, November/December: 22-27.

Löwgren, J. \& Stolterman, E. (2004). Thoughtful Interaction Design: Design Perspective on Information Technology. Cambridge, Mass: The MIT Press.

Lundberg, J. (2005). Shaping online news: Genre perspectives on interaction design. Linköping Studies in Science and 
Technology, Dissertation No. 918. Linköping, Sweden: Linköpings universitet. Available at: http://urn.kb.se/ resolve?urn/urn:nbn:se:liu:diva-5020 (accessed 1 May 2006).

Nelson, H., \& Stolterman, E. (2003). The design way: Intentional change in an unpredictable world. Englewood Cliffs, $\mathrm{NJ}$ : Educational Technology Publications.

Newman, W. \& Landay, J. A. (2000). Sitemaps, storyboards, and specifications: A sketch of web site design practice. In Proceedings of the conference on Designing interactive systems: processes, practices, methods, and techniques (pp. 263-274). New York: ACM Press.

Newman, W. M., \& Lamming, M.G. (1995). Interactive system design. Harlow, UK: Addison-Wesley.

Ochs, E., Gonzales, P., \& Jacoby, S. (1996). When I come down I'm in the domain state": Grammar and graphic representation in the interpretative activity of physicists. In E. Ochs, E. Schegloff, \& S. Thompson (Eds.), Interaction grammar (pp. 328-369). Cambridge, UK: Cambridge University Press.

Ochs, E., Jacoby, S., \& Gonzales, P. (1994). Interpretative journeys: How physicists talk and travel through graphic space. Configurations, 2(1), 151-172.

Pomerantz, A., \& Fehr, B. J. (1997). Conversation analysis: An approach to the study of social action as sense making practices. In T. A. van Dijk (Ed.), Discourse as social interaction (pp. 64-91). London: Sage Publications.

Robertson, T. (1996). Embodied actions in time and place: The design of a multimedia, educational computer game. Computer Supported Cooperative Work: The Journal of Collaborative Computing, 5(4), 127.

Robertson, T. (1997). Cooperative work and lived cognition: A taxonomy of embodied actions. In Proceedings of the Fifth European conference on Computer-supported cooperative work (pp. 205-220). Dordrecht: Kluwer.

Sato, S. \& Salvador, T. (1999) Playacting and focus troupes: Theater techniques for creating quick, intense, immersive, and engaging focus group sessions. Interactions, September/ October: $35-41$.

Schön, D. (1983). The reflective practitioner: How professionals think in action. New York: Basic Books.

Schön, D. (1987). Educating the reflective practitioner. San Francisco, CA: Jossey-Bass.

Shneiderman, B., \& Plaisant, C. (2004). Designing the user interface: Strategies for effective humancomputer interaction (4th ed). Harlow, UK: Addison-Wesley.

Sinha, K., \& Landay, J. A. (2001). Visually prototyping perceptual user interfaces through multimodal storyboarding. Proceedings of the 2001 workshop on Perceptive user interfaces (pp. 14). New York: ACM Press.

Snyder, C. (2003). Paper prototyping: The fast and easy way to design and refine user interfaces. San Francisco, CA: Morgan Kaufmann Publishers.

Sundholm, H., Ramberg, R. \& Artman, H. (2004). Learning conceptual design: Activities with electronic whiteboards. In M. Agger Eriksen, L. Malmborg, J. Nilsen (Eds.), CADE2004 web proceedings of computers in art and design education conference. Copenhagen, Denmark and Malmö, Sweden: Copenhagen Business School and Malmö University. Available at: http://www.asp.cbs.dk/cade2004/proceedings/ (accessed 1 May 2006).

Svanæs, D. (2000). Understanding interactivity: Steps to a phenomenology of humancomputer interaction. Dissertation,
Norges teknisknaturvitenskaplige universitet, Trondheim, Norway.

Tang, J. C. (1989). Toward an understanding of the use of shared workspaces by design teams. Dissertation, Stanford University, Stanford, CA.

Tuikka, T. (2002). Remote concept design from an activity theory perspective. In Proceedings of the 2002 ACM conference on Computer supported cooperative work (pp. 186-195). New York: ACM Press.

Van Welie, M., \& van der Veer, G.C. (2003). Pattern languages in interaction design: Structure and organization. Proceedings of Interact '03 (pp. 527-534). Amsterdam: IOS Press.

Werle, P., Kilander, F., Jonsson, M., Lönnqvist, P. \& Jansson, C. G. (2001). A ubiquitous service environment with active documents for teamwork support. In Ubicomp 2001: Ubiquitous computing, Third international conference (pp. 139-155). London: Springer-Verlag.

Woolman, M. (2002). Digital information graphics. London: Thames \& Hudson.

Wulff, W., Evans, S. \& Rheinfrank, J. (1990). Animating interfaces. In Proceedings of the 1990 ACM conference on Computer-supported cooperative work (pp. 241254). New York: ACM Press.

\section{CORRESPONDENCE}

Correspondence: Mattias Arvola,

Linköpings universitet,

Department of Information and Computer Science, SE-581 83 Linköping, Sweden.

E-mail: matar@ida.liu.se

Published online 2006-12-11

ISSN 1749-3463 print/ ISSN 1749-3471

DOI: 10.1080/17493460601117272

(C) 2006 Artifact 